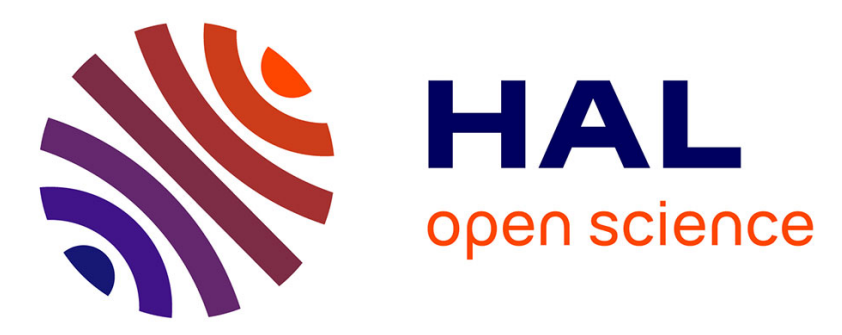

\title{
The optimal carbon sequestration in agricultural soils: does the dynamics of the physical process matter?
}

Lionel Ragot, Katheline Schubert

\section{To cite this version:}

Lionel Ragot, Katheline Schubert. The optimal carbon sequestration in agricultural soils: does the dynamics of the physical process matter?. 2006. halshs-00115685

\section{HAL Id: halshs-00115685 \\ https://shs.hal.science/halshs-00115685}

Submitted on 22 Nov 2006

HAL is a multi-disciplinary open access archive for the deposit and dissemination of scientific research documents, whether they are published or not. The documents may come from teaching and research institutions in France or abroad, or from public or private research centers.
L'archive ouverte pluridisciplinaire HAL, est destinée au dépôt et à la diffusion de documents scientifiques de niveau recherche, publiés ou non, émanant des établissements d'enseignement et de recherche français ou étrangers, des laboratoires publics ou privés. 


\title{
Centre d'Economie de la Sorbonne
}

The optimal carbon sequestration in agricultural soils : does the dynamics of the physical process matter?

\author{
Lionel RAGOT
}

Katheline SCHUBERT

2006.40
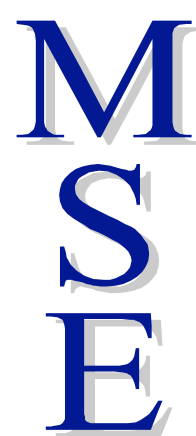

la

de

CENTRE NATIONAL

DE LARECHERCHE

SCIENTFIQUE 


\title{
The optimal carbon sequestration in agricultural soils: does the dynamics of the physical process matter?
}

\author{
Lionel Ragot ${ }^{a, b}$ and Katheline Schubert ${ }^{a}$ \\ ${ }^{a}$ CES, Université de Paris $1^{*}$ \\ ${ }^{b}$ MÉDEE, Université de Lille 1
}

13th March 2006

${ }^{*}$ The authors acknowledge financial support from the French Ministry of Ecology and Sustainable Development (APR GICC 2002). The usual disclaimers apply. 


\title{
Résumé
}

Le Protocole de Kyoto, entré en vigueur en février 2005, autorise les pays signataires à recourir à des "activités supplémentaires" permettant en particulier la séquestration de carbone dans les sols. Les travaux existants qui étudient la sequestration optimale de carbone reconnaissent l'importance du processus temporel de séquestration, mais négligent le fait que ce processus est dissymétrique. Ce papier prend en compte explicitement la dynamique de la séquestration. Sa première contribution est technique : nous résolvons un problème de contrôle optimal à deux phases et processus dynamique dissymétrique. Sa seconde contribution est empirique : nous montrons que l'erreur commise en supposant la séquestration immédiate peut être très significative, et simulons le sentier optimal de séquestration / déséquestration pour des fonctions de bénéfice, de dommage et de coût particulières.

\section{Codes JEL : C61, H23, Q01, Q15}

Mots clés : environnement, agriculture, séquestration de carbone, Protocole de Kyoto, contrôle optimal.

\begin{abstract}
The Kyoto Protocol, which came in force in February 2005, allows countries to resort to "supplementary activities" consisting particularly in carbon sequestration in agricultural soils. Existing papers studying the optimal carbon sequestration recognize the importance of the temporality of sequestration, but overlook the fact that it is a dissymmetric dynamic process. This paper takes explicitely into account the temporality of sequestration. Its first contribution is technical: we solve an optimal control problem with two stages and a dissymmetric dynamic process. The second contribution is empirical: we show that the error made when sequestration is supposed immediate can be very significant, and we exhibit numerically the optimal path of sequestation / de-sequestration for specific benefit, damage and cost functions, and a calibration that mimics roughly the world conditions.
\end{abstract}

JEL Classification: C61, H23, Q01, Q15

Keywords: Environment, agriculture, carbon sequestration, Kyoto Protocol, optimal control. 


\section{Introduction}

The Kyoto Protocol, ratified by the European countries in 2002 and in force from February 2005, allows countries to resort to "supplementary activities" consisting in the sequestration of carbon in forests and in agricultural soils (Articles 3.3 and 3.4). The emissions trapped by such volontary activities, set up after 1990, can be deduced from the emissions of greenhouse gas. They can be the result of afforestation projects (Article 3.3) or of changes of practices in the agricultural and forestry sectors (Article 3.4). As far as this last article is concerned, the list of eligible activities proposed by the IPCC gives appreciable opportunities of reduction of emissions to countries possessing significant surfaces of agricultural land. For example, gross French emissions of greenhouse gas were estimated at $148 \mathrm{MtC}$ in 2000. France emits low levels of GHG per capita and will encounter difficulties in further reducing its emissions, in part because of the importance of French nuclear energy generating capacity. Given the area of land devoted to agriculture, the prospects opened by Article 3.4 may be of interest for the French policy of greenhouse gas mitigation. The French National Institute for Agricultural Research has recently estimated the potential additional carbon storage for the next 20 years, between 1 and 3 $\mathrm{MtC} /$ year, for the whole of mainland France (INRA (2002)). This potential is equivalent to 1 to $2 \%$ of annual French greenhouse gas emissions, a large proportion of the efforts required to comply with the commitments to the Kyoto Protocol. At the European level, this potential is estimated at 1.5 to $1.7 \%$ of the EU-15 anthropogenic $\mathrm{CO}_{2}$ emissions during the first commitment period (European Climate Change Program (2003)).

The Bonn Agreement (COP6bis) in July 2001 clarifies the implementation of Article 3.4: eligible activities in agriculture comprise "cropland management", "grazing land management" and "revegetation", provided that these activities have occured since 1990 and are human-induced. Carbon sequestration can occur either through a reduction in soil disturbance (zero tillage or reduced tillage, set-aside land, growth of perennial crops...) or through an increase of the carbon input to the soil (animal manure, sewage sludge, compost...). Switching from conventional arable agriculture to other land-uses with higher carbon input or reduced disturbance can also increase the soil carbon stock (conversion of arable land to grassland or woodland, organic farming...).

Lal et al. (1998) provide estimates of the carbon sequestration potential of agricultural management options in the USA. A few studies present estimations of agricultural soil carbon sequestration potentials for EU-15 (see European Climate Change Programme (2003)), and one study does the same for France (INRA (2002)). They all show that soil carbon sequestration is a non-linear process. Increases in soil carbon are often greatest soon after a land use or land management change is implemented. There is also a sink saturation effect: as the soil reaches a new equilibrium, the rate of change decreases, so that after 20 to 100 years a new equilibrium is reached and no further change takes place. Moreover, by changing agricultural management or land-use, soil carbon is lost more rapidly than it accumulates (Smith et al. (1996), INRA (2002)). Carbon de-sequestation is far faster than sequestration or, to put it differently, carbon storage in agricultural soils takes far more time than carbon release (the unit of measure of the storage time is tens of years, the one of release is years, see INRA (2002)). 
The aim of this paper is to study the optimal policy of carbon sequestration in agricultural soils. While many technical papers try to quantify the potential of carbon sequestration, there are very few papers studying the optimal path of carbon sequestration. To the best of our knowledge, the paper by Feng, Zhao and Kling (2002) is the only one. But their dynamic representation of the process is limited by the assumption that the sequestration potential of a unit of land on which a change in land use or land management takes place is instantaneously obtained. Technical papers recognize the importance of the temporality of sequestration, and we take in this paper this temporality explicitely into account. Moreover, we also take into account the fact that sequestration is a dissymmetric dynamic process, which most experts in the field of agriculture consider determining (INRA (2002)). Anyhow, the question is: what should the dissymmetry of the process be important at all? The answer to this question is obvious in a decentralized framework, where agents can be incited to sequester carbon by an appropriate policy, and then be incited to stop using the sequestering practices if the policy is not permanent. In the case of the optimal policy that we study here, temporary sequestration could be optimal if the terms of the trade-off between emissions abatement and carbon sequestration in order to reduce the stock of carbon in the atmosphere change in the course of time. These terms could change because of a technical progress enhancing the possibilities of abatement, or because of the characteristics of the dynamic process of sequestration / de-sequestration. We focus here on the second possibility.

We adapt the Feng, Zhao and Kling's (2002) model to take into account explicitly the dynamics of the sequestration process. The main characteristics of the model are the following. The economic activity causes carbon emissions that accumulate in the atmosphere. Benefits are associated to this emissions - or, equivalently, emissions reduction is costly -, and damages to the atmospheric carbon stock. Sequestration has a cost, depending on how much land is devoted to it. When a change of practice occurs on a unit of land in order to enhance its carbon sequestration, it stores its potential gradually; when the unit of land returns to the usual practice, it releases carbon more rapidly than it has stored it. The total amount of land on which a change of practice can take place is bounded from above. In the same way, at each date, the amount of new land that can be used to store carbon is bounded from above, as well as the amount of land that can go back to the usual practice. This assumption expresses in a simple way the existence of adjustment costs and of physical limits to the land-use changes. The sequestration / de-sequestration process is supposed irreversible, in the sense that it is impossible to sequester again on a unit of land that has already been used for sequestration and then went back to the usual practice. The problem is then to find at each date the optimal carbon emissions and the amount of land newly devoted to sequestration or de-sequestration, subject to the evolution of the carbon and land stocks and of the constraints. We characterize analytically the different possible solutions. Then, we calibrate the model and make numerical simulations that allow us to compare our solutions to the ones obtained when the dynamics and the dissymmetry of the process are not taken into account.

Section 2 presents the modelling of the sequestration / de-sequestration process. Section 3 is devoted to the exposition and the analytical resolution of the dynamic optimization problem taking the temporality and the dissymmetry of this process into consideration. In section 4, numerical simulations 
allow us to exhibit the optimal path of carbon sequestration, for specific benefit of emissions, damage and cost of sequestration functions, and to compare it with the path obtained when sequestration and de-sequestration are taken to be immediate. Section 5 concludes.

\section{The dynamics of carbon sequestration in agricultural soils}

The total amount of agricultural land is supposed to be $B$, constant over time and exogenous. Land is homogeneous and produces a unique agricultural good. The different units of land may however differ according to the agricultural practices used on them. Two types of practices are distinguished: the "usual" practice and a "sequestering" practice, allowing land to store more carbon. All units of land are supposed to be initially cultivated with the usual practice.

Physical studies clearly show that additional sequestration is a non-linear process: it is high in the first years following the change of practice, then decreases and tends towards zero as the new equilibrium is approached. We adopt here, following the results of Hénin and Dupuis (1945), an exponential approximation of the sequestration process.

The maximal amount of carbon that can be stored in a unit of land's soil is $c s^{*}$. Let $c s(t, z)$ represent the amount of carbon in the soil at date $t$ for a change of practice taking place at date $z$, and $c s_{0}$ the amount of carbon stored with the usual practice $\left(c s^{*}>c s_{0} \geq 0\right)$. The dynamics of sequestration in a unit of land is then

$$
c s(t, z)=c s^{*}+\left(c s_{n}-c s^{*}\right) e^{-s(t-z)}, \quad t \geq z,
$$

where $s>0$ is the parameter of speed of the sequestration process.

Let us now consider a unit of land returning to the usual practice at date $\varsigma$ after having experienced the first change of practice at date $z \cdot \operatorname{cs}(\varsigma, z)$ is the amount of carbon that the sequestering practice has allowed the land to store until date $\varsigma$, and $c s(t, \varsigma, z)$ the amount of carbon remaining in the soil at date $t$. We have

$$
\begin{aligned}
c s(t, \varsigma, z) & =c s_{n}+\left(c s(\varsigma, z)-c s_{n}\right) e^{-s^{\prime}(t-\varsigma)}, \quad t \geq \varsigma \geq z \\
& =c s_{n}+\left(c s^{*}-c s_{n}\right)\left(1-e^{-s(\varsigma-z)}\right) e^{-s^{\prime}(t-\varsigma)}, \quad t \geq \varsigma \geq z,
\end{aligned}
$$

where $s^{\prime}>0$ is the parameter of speed of the de-sequestration process. The assumption $s^{\prime}>s$ will allow us to take into account the fact that the storage process is slower than the release process.

Let us assume first that the only possible change of practice is from the usual to a sequestering one (no possibility of return to the usual practice). The aggregate carbon stock stored in agricultural soils at $t$ is then defined by

$$
\begin{aligned}
C S(t) & =c s_{n} B+\int_{0}^{t} a(z)\left(c s(t, z)-c s_{n}\right) d z \\
& =c s_{n} B+\left(c s^{*}-c s_{n}\right) \int_{0}^{t} a(z)\left(1-e^{-s(t-z)}\right) d z,
\end{aligned}
$$

where $a(z)$ is the number of units of land that moved from the usual practice to a sequestering one at date $z$. Feng et al. (2002) suppose that because of various technical and economic constraints, the 
number of units of land on which a change of practice can take place at each date is bounded from above: $a(z) \leq \bar{a} \forall z$. To avoid unessential technical difficulties (see footnote 2), we make the stronger assumption that $a$ is a discrete variable that can only take the two values 0 and $\bar{a}$ : the number of units of land on which the practice can change is either nil or maximum.

The fact that the change of practice can take place at different dates on different units of land introduces an heterogeneity among the units, even if land is initially homogeneous. At date $t$, all the units which have adopted a sequestering practice do not necessarily store the same amount of carbon, the amount stored by each of them depending on the date of the change of practice.

Let us suppose now that a sequence usual practice / sequestering practice / usual practice is possible. There exist for a given unit of land three conceivable configurations ${ }^{1}$ at date $t$ :

- either it has been cultivated with the usual practice from the beginning, and the carbon stored is $c s_{n}$;

- or it has experienced a single change of practice at date $z<t$, and the carbon stored is $c s(t, z)$ given by equation (1);

- or it has experienced the two changes of practice, respectively at dates $z$ and $\varsigma$ with $z<\varsigma<t$, and the carbon stored is $c s(t, \varsigma, z)$ given by equation $(2)$.

The calculation of the aggregate carbon stock is complicated because of the heterogeneity due to the timing of sequestration. Nevertheless, in the case of the social optimum and under the assumption of homogeneity of the land, the units of land which must come back to the usual practice are necessarily those which have changed practice last (last in - first out principle). The benefit of a return to the usual practice on a given unit of land is indeed independant of the carbon stored in its soil. Besides, the social damage due to this return is all the smaller since this carbon stock is low, which corresponds to the last unit having changed practice. The aggregate stock then writes

$$
C S(t)=c s_{n} B+\int_{0}^{T^{\prime}} a(z)\left(c s(t, z)-c s_{n}\right) d z-\int_{T^{\prime}}^{t} b(z) r s(t, z) d z
$$

with $T^{\prime}$ the date at which the carbon release begins and $r s(t, z)$ the "virtual release" at date $t$ in the $b(z)$ units of lands that went back to the usual practice at date $z$ (cf. figure 1). Sequestration begins in a given unit of land at date $\chi(z)$ and stops at date $z$. The amount of carbon stored in the soil of this unit at this date is $c s(z, \chi(z))$. The amount of carbon stored at date $t$ is $c s(t, z, \chi(z))$. If the sequestering practice had continued until date $t$ the sequestration would have been equal to $c s(t, \chi(z))$. The difference between this virtual storage and the real one is $r s(t, z)$. We then have

$$
\begin{aligned}
r s(t, z) & =c s(t, \chi(z))-c s(t, z, \chi(z)) \\
& =\left(c s^{*}-c s_{n}\right)\left(\left(1-e^{-s(t-\chi(z))}\right)-\left(1-e^{-s(z-\chi(z))}\right) e^{-s^{\prime}(t-z)}\right) .
\end{aligned}
$$

\footnotetext{
${ }^{1}$ We do not consider situations in which a unit of land would experience three successive changes of practice.
} 


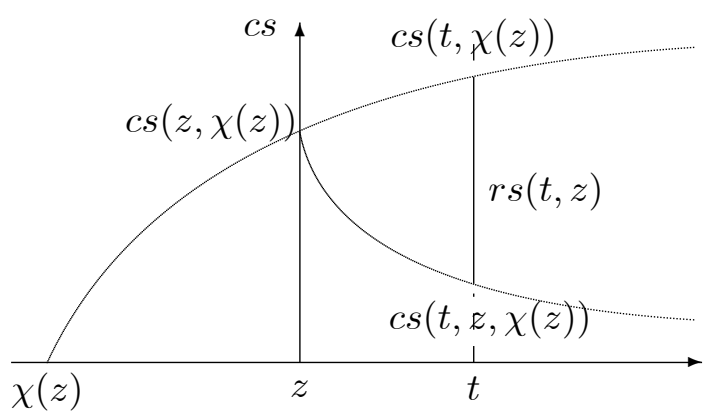

Figure 1: Carbon storage and release

The last in - first out principle allows us to define $\chi(z)$ by

$$
\int_{\chi(z)}^{T^{\prime}} a(\tau) d \tau=\int_{T^{\prime}}^{z} b(\tau) d \tau .
$$

For the same reasons than in the case of $a(t)$, we make the assumption that the number of units of land that can go back to the usual practice at each date is either 0 or $\bar{a}: b(t)=\{0, \bar{a}\} \forall t$.

The aggregate carbon stock sequestered in agricultural soils is finally:

$$
\begin{cases}C S(t)=c s_{n} B+\left(c s^{*}-c s_{n}\right) \int_{0}^{t} a(z)\left(1-e^{-s(t-z)}\right) d z & \forall t \leq T^{\prime} \\ C S(t)=c s_{n} B+\left(c s^{*}-c s_{n}\right) \int_{0}^{T^{\prime}} a(z)\left(1-e^{-s(t-z)}\right) d z & \\ -\left(c s^{*}-c s_{n}\right) \int_{T^{\prime}}^{t} b(z)\left(\left(1-e^{-s(t-\chi(z))}\right)-\left(1-e^{-s(z-\chi(z))}\right) e^{-s^{\prime}(t-z)}\right) d z & \forall t>T^{\prime},\end{cases}
$$

and the corresponding flow of carbon emissions trapped at each date in the soils is:

$$
\begin{cases}F(t)=\left(c s^{*}-c s_{n}\right) s \int_{0}^{t} a(z) e^{-s(t-z)} d z & \forall t \leq T^{\prime} \\ F(t)=\left(c s^{*}-c s_{n}\right) s \int_{0}^{T^{\prime}} a(z) e^{-s(t-z)} d z & \\ -\left(c s^{*}-c s_{n}\right) \int_{T^{\prime}}^{t} b(z)\left(s e^{-s(t-\chi(z))}+s^{\prime}\left(1-e^{-s(z-\chi(z))}\right) e^{-s^{\prime}(t-z)}\right) d z & \forall t>T^{\prime} .\end{cases}
$$

Finally, the stock of agricultural land cultivated with the sequestering practice at date $t$ is:

$$
\begin{aligned}
& \begin{cases}A(t)=\int_{0}^{t} a(z) d z & \forall t \leq T^{\prime} \\
A(t)=\int_{0}^{T^{\prime}} a(z) d z-\int_{T^{\prime}}^{t} b(z) d z & \forall t>T^{\prime}\end{cases} \\
& \text { with } 0 \leq \\
& \text { A }(t) \leq B, a(t)=\{0, \bar{a}\} \text { and } b(t)=\{0, \bar{a}\} \quad \forall t
\end{aligned}
$$

\section{The optimal solution}

\subsection{The social planner's program}

The social planner maximizes the total surplus associated to the emissions of carbon by the economic activity, composed of the difference between the benefits of emissions and the sum of the costs of carbon sequestration in agricultural soils and of the damage of climate change.

The carbon stock in the atmosphere is subject to a natural assimilation process at the constant rate $\delta>0$; besides, it is augmented by net emissions, equal to raw emissions $E(t)$ minus emissions removed 
from the atmosphere by sequestration in agricultural soils $F(t)$. The equation of accumulation of the carbon stock is then

$$
\dot{S}(t)=-\delta S(t)+E(t)-F(t)
$$

where $F(t)$ is given by equation (5).

The initial carbon stock is given, $S(0)=S_{0}>0$.

The benefits of emissions are $B(E(t))$, with $B^{\prime}(E(t))>0$ and $B^{\prime \prime}(E(t)) \leq 0$.

The damage function is $D(S(t))$, with $D^{\prime}(S(t))>0$. We do not make any a priori assumption on $D^{\prime \prime}(S(t))$ : the marginal damage can be decreasing, constant or increasing.

The cost of sequestration is $C(A(t))$, with $C^{\prime}(A(t))>0$ and $C^{\prime \prime}(A(t))>0$. This cost is an opportunity cost and also a cost associated to the new equipment that the change of practice requires.

The social discount rate is $r$, supposed constant.

The date at which carbon release begins to take place is $T^{\prime}$.

The social planner seeks to maximize (with $\widetilde{c}=c s^{*}-c s_{n}$ )

$$
\max V=\int_{0}^{\infty} e^{-r t}(B(E(t)-D(S(t))-C(A(t))) d t
$$

subject to

$$
\begin{cases}\dot{S}(t)=-\delta S(t)+E(t)-F(t) & \\ \dot{A}(t)=a(t)-b(t) & \forall t \leq T^{\prime} \\ \begin{cases}F(t)=\widetilde{c} s \int_{0}^{t} a(z) e^{-s(t-z)} d z & \\ F(t)=\widetilde{c} s \int_{0}^{T^{\prime}} a(z) e^{-s(t-z)} d z & \\ -\widetilde{c} \int_{T^{\prime}}^{t} b(z)\left(s e^{-s(t-\chi(z))}+s^{\prime}\left(1-e^{-s(z-\chi(z))}\right) e^{-s^{\prime}(t-z)}\right) d z & \forall t>T^{\prime} \\ \int_{\chi(z)}^{T^{\prime}} a(\tau) d \tau=\int_{T^{\prime}}^{z} b(\tau) d \tau & \\ 0 \leq A(t) \leq B, a(t)=\{0, \bar{a}\} \text { and } b(t)=\{0, \bar{a}\} \quad \forall t & \forall t \\ S(0)=S_{0} \text { and } A(0)=0 \text { given. } & \end{cases} \end{cases}
$$

The flow of carbon stored in agricultural soils at instant $t, F(t)$, is determined differently depending on the relevant stage: carbon storage (before $T^{\prime}$ ) or carbon release (after $T^{\prime}$ ). The problem is then a two-stage optimal control problem. In order to solve it, we adapt to our case the method proposed by Tomiyama (1985), Tomiyama and Rossana (1989) and Saglam (2002) for this type of problems. The derivation of the first order necessary conditions of optimality and of the matching conditions in the general case is left to Appendix A.

\subsection{Before $T^{\prime}$ : sequestration}

The social planner solves an optimization program in finite horizon, considering that the horizon $T^{\prime}$ and the value function of the program after $T^{\prime} V_{+}\left(S\left(T^{\prime}\right), A\left(T^{\prime}\right)\right)$ are given. By definition of $T^{\prime}$, we 
have $b(t)=0 \forall t \leq T^{\prime}$. The social planner's program then writes

$$
\left\{\begin{array}{l}
\max \int_{0}^{T^{\prime}} e^{-r t}(B(E(t))-D(S(t))-C(A(t))) d t+V_{+}\left(S\left(T^{\prime}\right), A\left(T^{\prime}\right)\right) \\
\dot{S}(t)=-\delta S(t)+E(t)-\widetilde{c} s \int_{0}^{t} a(z) e^{-s(t-z)} d z \\
\dot{A}(t)=a(t) \\
0 \leq A(t) \leq B \text { and } a(t)=\{0, \bar{a}\} \forall t \\
S(0)=S_{0}, A(0)=0 \text { given. }
\end{array}\right.
$$

We note $\lambda_{1-}$ the shadow price of the carbon stock $S$ and $\lambda_{2-}$ the one of the land used for sequestration $A$. The current value Hamiltonian of this program is then (see Appendix A):

$$
\begin{aligned}
\mathcal{H}_{-}= & e^{-r t}(B(E(t))-D(S(t))-C(A(t)))+\lambda_{1-}(t)(-\delta S(t)+E(t))+\lambda_{2-}(t) a(t) \\
& -\widetilde{c} s a(t) \int_{t}^{T^{\prime}} \lambda_{1-}(z) e^{-s(z-t)} d z .
\end{aligned}
$$

First of all, the Hamiltonian is linear in the control variable $a(t)$. The coefficient associated to $a(t)$ in the Hamiltonian is

$$
\alpha(t)=\lambda_{2-}(t)-\widetilde{c} s \int_{t}^{T^{\prime}} \lambda_{1-}(z) e^{-s(z-t)} d z
$$

It represents the difference between the marginal benefit of sequestration and its marginal cost. The marginal benefit is the sum of the flows of carbon sequestered until $T^{\prime}$ by an additional unit of land devoted to sequestration at $t$, evaluated at the (negative) shadow value of the carbon stock $\lambda_{1-}$. The marginal cost is the (negative) shadow price of the land used for sequestration $\lambda_{2-}$. As long as this coefficient $\alpha(t)$ is positive, the benefit of sequestration is greater than its cost and $a(t)=\bar{a}$; when the coefficient becomes negative, $a(t)=0^{2}$. It may happen that sequestration stops while $\alpha(t)$ is still positive, if all the lands suitable for sequestration are already used. The date $T$ at which sequestration stops can then be:

- $T_{1}$ in the case of a corner solution, with $A\left(T_{1}\right)=B$ and $\alpha\left(T_{1}\right)>0$;

- $T_{2}$ in the case of an interior solution, with $A\left(T_{2}\right)<B$ and $\alpha\left(T_{2}\right)=0$.

Besides, between 0 and $T$ (equal to $T_{1}$ or $T_{2}$ ) we have $\dot{A}(t)=\bar{a}$, which implies

$$
A(t)=\left\{\begin{array}{l}
\bar{a} t, t \leq T \\
A(T)=\bar{a} T, t \in\left[T, T^{\prime}\right] .
\end{array}\right.
$$

The first order necessary conditions are (see Appendix A):

$$
\begin{aligned}
\frac{\partial \mathcal{H}_{-}}{\partial E(t)} & =0 \Leftrightarrow e^{-r t} B^{\prime}(E(t))+\lambda_{1-}(t)=0, \\
\frac{\partial \mathcal{H}_{-}}{\partial S(t)}+\dot{\lambda}_{1-}(t) & =0 \Leftrightarrow-e^{-r t} D^{\prime}(S(t))-\lambda_{1-}(t) \delta+\dot{\lambda}_{1-}(t)=0, \\
\frac{\partial \mathcal{H}_{-}}{\partial A(t)}+\dot{\lambda}_{2-}(t) & =0 \Leftrightarrow-e^{-r t} C^{\prime}(A(t))+\dot{\lambda}_{2-}(t)=0 .
\end{aligned}
$$

\footnotetext{
${ }^{2}$ Without the assumption that $a(t)$ is a discrete variable, we could have had $\alpha(t)=0$ for an interval of values of $t$, that could not have been reduced to the single value T. Feng et al. (2002) obtain this kind of solution. This would have been untractable in our problem.
} 
Equations (12) and (13) allow us to obtain the growth rate of emissions:

$$
\frac{\dot{E}(t)}{E(t)}=-\frac{B^{\prime}(E(t))}{E(t) B^{\prime \prime}(E(t))}\left(\frac{D^{\prime}(S(t))}{B^{\prime}(E(t))}-(r+\delta)\right) .
$$

Besides, the equation of accumulation of the carbon stock is

$$
\dot{S}(t)=-\delta S(t)+E(t)-F(t)
$$

with

$$
F(t)=\widetilde{c} \bar{a}\left\{\begin{array}{l}
\left(1-e^{-s t}\right), \quad 0 \leq t \leq T \\
e^{-s t}\left(e^{s T}-1\right), \quad T \leq t \leq T^{\prime} .
\end{array}\right.
$$

These two dynamic equations allow us to obtain $E(t)$ and $S(t) \forall t \in\left[0, T^{\prime}\right]$, as functions of $E(0)$ and $T$ which are still unknown.

Using equation (11), equation (14) integrates into:

$$
\lambda_{2-}(t)=\left\{\begin{array}{l}
\lambda_{2-}(0)+\int_{0}^{t} e^{-r z} C^{\prime}(A(z)) d z, \quad 0 \leq t \leq T, \\
\lambda_{2-}(T)-\frac{C^{\prime}(A(T))}{r}\left(e^{-r t}-e^{-r T}\right), \quad T \leq t \leq T^{\prime} .
\end{array}\right.
$$

It is now possible to calculate $\alpha(T)$, using equations (10), (12) and (18):

$$
\alpha(T)=\lambda_{2-}(0)+\int_{0}^{T} e^{-r z} C^{\prime}(A(z)) d z+\widetilde{c} s e^{s T} \int_{T}^{T^{\prime}} e^{-(r+s) z} B^{\prime}(E(z)) d z,
$$

where $T^{\prime}, \lambda_{2-}(0)$ and $E(z)$ are still unknown.

\subsection{After $T^{\prime}:$ de-sequestration}

$T^{\prime}$ is by definition the date at which de-sequestration begins. Then $a(t)=0 \forall t \geq T^{\prime}$.

The values of the stocks $S\left(T^{\prime}\right)$ and $A\left(T^{\prime}\right) \leq B$ are taken as given and constitute the initial conditions of the problem after $T^{\prime}$. The social planner's program writes

$$
\left\{\begin{array}{l}
\max V_{+}=\int_{T^{\prime}}^{\infty} e^{-r t}(B(E(t))-D(S(t))-C(A(t))) d t \\
\dot{S}(t)=-\delta S(t)+E(t)-F(t) \\
\dot{A}(t)=-b(t) \\
F(t)=\widetilde{c} s \int_{0}^{T^{\prime}} a(z) e^{-s(t-z)} d z-\widetilde{c} \int_{T^{\prime}}^{t} b(z)\left(s e^{-s(t-\chi(z))}+s^{\prime}\left(1-e^{-s(z-\chi(z))}\right) e^{-s^{\prime}(t-z)}\right) d z \\
\int_{\chi(z)}^{T^{\prime}} a(\tau) d \tau=\int_{T^{\prime}}^{z} b(\tau) d \tau \\
0 \leq A(t) \leq B \text { and } b(t)=\{0, \bar{a}\} \quad \forall t \\
S\left(T^{\prime}\right) \text { and } A\left(T^{\prime}\right) \text { given. }
\end{array}\right.
$$

Let $\lambda_{1+}$ be the shadow price of $S$ and $\lambda_{2+}$ the one of $A$. The current value Hamiltonian of this problem is then (see Appendix A):

$$
\begin{aligned}
\mathcal{H}_{+}= & e^{-r t}(B(E(t))-D(S(t))-C(A(t))) \\
& +\lambda_{1+}(t)\left(-\delta S(t)+E(t)-\widetilde{c} s \int_{0}^{T^{\prime}} a(z) e^{-s(t-z)} d z\right)-\lambda_{2+}(t) b(t) \\
& +\widetilde{c} b(t) \int_{t}^{\infty} \lambda_{1+}(z)\left(s e^{-s(z-\chi(t))}+s^{\prime}\left(1-e^{-s(t-\chi(t))}\right) e^{-s^{\prime}(z-t)}\right) d z
\end{aligned}
$$


The Hamiltonian is linear in the control variable $b(t)$. The coefficient associated to $b(t)$ is

$$
\beta(t)=-\lambda_{2+}(t)+\widetilde{c} \int_{t}^{\infty} \lambda_{1+}(z)\left(s e^{-s(z-\chi(t))}+s^{\prime}\left(1-e^{-s(t-\chi(t))}\right) e^{-s^{\prime}(z-t)}\right) d z .
$$

It is the difference between the marginal benefit and the marginal cost associated to carbon release. The marginal benefit is the opposite of the (negative) shadow price of the land used for sequestration $\lambda_{2+}$. The marginal cost is the sum of the flows of carbon released from $t$ to infinity by an additional unit of land returning to the usual practice at $t$, evaluated at the (negative) shadow value of the carbon stock $\lambda_{1+}$. As long as this coefficient $\beta(t)$ is positive, the benefit of de-sequestration is greater than its cost and $b(t)=\bar{a}$; when it becomes negative, carbon release stops and $b(t)=0$. It may happen that release stops before $\beta(t)$ becomes negative, if all the units of land that have been used for sequestration are back to the usual practice. Let $T^{\prime \prime}$ be the date at which de-sequestration stops. Between $T^{\prime}$ and $T^{\prime \prime}$, we have $\dot{A}(t)=-\bar{a}$ and then

$$
A(t)=A\left(T^{\prime}\right)-\bar{a}\left(t-T^{\prime}\right)=\bar{a}\left(T+T^{\prime}-t\right), T^{\prime} \leq t \leq T^{\prime \prime} .
$$

As we have just pointed out, two configurations may occur:

- If $\beta$ never becomes negative after $T^{\prime}$, carbon release takes place until all land used for sequestration has returned to the usual practice. Date $T_{1}^{\prime \prime}$ is defined as the date at which this happens:

$$
A\left(T_{1}^{\prime \prime}\right)=0 \Leftrightarrow T_{1}^{\prime \prime}=T+T^{\prime} .
$$

- If there exists a date at which $\beta$ becomes negative, this date is denoted $T_{2}^{\prime \prime}$ (with $T^{\prime}<T_{2}^{\prime \prime}<T_{1}^{\prime \prime}$ ). We then have $\beta\left(T_{2}^{\prime \prime}\right)=0$ and $b(t)=0$ and $A(t)=A\left(T_{2}^{\prime \prime}\right) \forall t \geq T_{2}^{\prime \prime}$.

Notice that we have, for $t \in\left[T^{\prime}, T^{\prime \prime}\right]$ :

$$
\int_{\chi(t)}^{T} a(z) d z=\int_{T^{\prime}}^{t} b(z) d z \Leftrightarrow \bar{a} \int_{\chi(t)}^{T} d z=\bar{a} \int_{T^{\prime}}^{t} d z
$$

which allows us to obtain $\chi(t)$ :

$$
\chi(t)=T+T^{\prime}-t
$$

We show in Appendix A that the first order necessary conditions for an interior solution are:

$$
\begin{aligned}
\frac{\partial \mathcal{H}_{+}}{\partial E(t)} & =0 \Leftrightarrow e^{-r t} B^{\prime}(E(t))+\lambda_{1+}(t)=0, \\
\frac{\partial \mathcal{H}_{+}}{\partial S(t)}+\dot{\lambda}_{1+}(t) & =0 \Leftrightarrow-e^{-r t} D^{\prime}(S(t))-\lambda_{1+}(t) \delta+\dot{\lambda}_{1+}(t)=0, \\
\frac{\partial \mathcal{H}_{+}}{\partial A(t)}+\dot{\lambda}_{2+}(t) & =0 \Leftrightarrow-e^{-r t} C^{\prime}(A(t))+\dot{\lambda}_{2+}(t)=0,
\end{aligned}
$$

while the transversality conditions write

$$
\begin{aligned}
& \lim _{t \rightarrow \infty} \lambda_{1+}(t) S(t)=0, \\
& \lim _{t \rightarrow \infty} \lambda_{2+}(t) A(t)=0 .
\end{aligned}
$$


Equations (24) and (25) allow us to obtain, as in the first stage of the problem, the growth rate of emissions:

$$
\frac{\dot{E}(t)}{E(t)}=-\frac{B^{\prime}(E(t))}{E(t) B^{\prime \prime}(E(t))}\left(\frac{D^{\prime}(S(t))}{B^{\prime}(E(t))}-(r+\delta)\right) .
$$

Besides, the equation of accumulation of the carbon stock still writes

$$
\dot{S}(t)=-\delta S(t)+E(t)-F(t)
$$

but the flow of carbon sequestered in agricultural soils is now (using equation (5) and $\left.\chi(z)=T+T^{\prime}-z\right)$ :

$$
\begin{aligned}
& F(t)=\widetilde{c} \bar{a} e^{-s t}\left(e^{s T}-1\right)-\widetilde{c} \bar{a} \times \\
& \left\{\begin{array}{l}
e^{-s(t-T)}\left(1-e^{-s\left(t-T^{\prime}\right)}\right)+\left(1-e^{-s^{\prime}\left(t-T^{\prime}\right)}\right)-\frac{s^{\prime}}{s^{\prime}-2 s} e^{s\left(T+T^{\prime}\right)} e^{-s^{\prime} t}\left(e^{\left(s^{\prime}-2 s\right) t}-e^{\left(s^{\prime}-2 s\right) T^{\prime}}\right), T^{\prime} \leq t \leq T^{\prime \prime} \\
e^{-s(t-T)}\left(1-e^{-s\left(T^{\prime \prime}-T^{\prime}\right)}\right)+e^{-s^{\prime} t}\left(e^{s^{\prime} T^{\prime \prime}}-e^{s^{\prime} T^{\prime}}\right)-\frac{s^{\prime}}{s^{\prime}-2 s} e^{s\left(T+T^{\prime}\right)} e^{-s^{\prime} t}\left(e^{\left(s^{\prime}-2 s\right) T^{\prime \prime}}-e^{\left(s^{\prime}-2 s\right) T^{\prime}}\right), t \geq T^{\prime \prime}
\end{array}\right.
\end{aligned}
$$

The two dynamic equations allow us to obtain $E(t)$ and $S(t) \forall t \in\left[T^{\prime}, \infty\left[\right.\right.$, as functions of $E\left(T^{\prime}\right)$, $S\left(T^{\prime}\right), T$ and $T^{\prime \prime}$ which are still unknown.

With

$$
A(t)=\left\{\begin{array}{l}
\bar{a}\left(T+T^{\prime}-t\right), \quad T^{\prime} \leq t \leq T^{\prime \prime} \\
A\left(T^{\prime \prime}\right)=\bar{a}\left(T+T^{\prime}-T^{\prime \prime}\right), \quad t \geq T^{\prime \prime}
\end{array}\right.
$$

equation (26) integrates into

$$
\lambda_{2+}(t)=\left\{\begin{array}{l}
\lambda_{2+}\left(T^{\prime}\right)+\int_{T^{\prime}}^{t} e^{-r z} C^{\prime}(A(z)) d z, \quad T^{\prime} \leq t \leq T^{\prime \prime} \\
\lambda_{2+}\left(T^{\prime \prime}\right)-\frac{C^{\prime}\left(A\left(T^{\prime \prime}\right)\right)}{r}\left(e^{-r t}-e^{-r T^{\prime \prime}}\right), \quad t \geq T^{\prime \prime} .
\end{array}\right.
$$

We then have

$$
\lambda_{2+}(t)=\lambda_{2+}\left(T^{\prime}\right)+\int_{T^{\prime}}^{T^{\prime \prime}} e^{-r z} C^{\prime}(A(z)) d z-\frac{C^{\prime}\left(A\left(T^{\prime \prime}\right)\right)}{r}\left(e^{-r t}-e^{-r T^{\prime \prime}}\right), \quad t \geq T^{\prime \prime},
$$

which implies

$$
\lim _{t \rightarrow \infty} \lambda_{2+}(t)=\lambda_{2+}\left(T^{\prime}\right)+\int_{T^{\prime}}^{T^{\prime \prime}} e^{-r z} C^{\prime}(A(z)) d z+\frac{C^{\prime}\left(A\left(T^{\prime \prime}\right)\right)}{r} e^{-r T^{\prime \prime}} .
$$

We will see below that the economy reaches in the long term a stationary state, where emissions, carbon stock and land used for sequestration are constant. Then, the transversality condition (28) implies that $\lim _{t \rightarrow \infty} \lambda_{2+}(t)=0$, and the previous equation allows us to write

$$
\lambda_{2+}\left(T^{\prime}\right)=-\int_{T^{\prime}}^{T^{\prime \prime}} e^{-r z} C^{\prime}(A(z)) d z-\frac{C^{\prime}\left(A\left(T^{\prime \prime}\right)\right)}{r} e^{-r T^{\prime \prime}} .
$$

We finally have

$$
\lambda_{2+}(t)=\left\{\begin{array}{l}
-\int_{t}^{T^{\prime \prime}} e^{-r z} C^{\prime}(A(z)) d z-\frac{C^{\prime}\left(A\left(T^{\prime \prime}\right)\right)}{r} e^{-r T^{\prime \prime}}, \quad T^{\prime} \leq t \leq T^{\prime \prime}, \\
-\frac{C^{\prime}\left(A\left(T^{\prime \prime}\right)\right)}{r} e^{-r t}, \quad t \geq T^{\prime \prime} .
\end{array}\right.
$$

It is now possible to calculate $\beta\left(T^{\prime \prime}\right)$, using equations (22), (35), (24) and $\chi(z)=T+T^{\prime}-z$ : $\beta\left(T^{\prime \prime}\right)=\frac{C^{\prime}\left(A\left(T^{\prime \prime}\right)\right)}{r} e^{-r T^{\prime \prime}}-\widetilde{c} \int_{T^{\prime \prime}}^{\infty} e^{-r z}\left(s e^{-s\left(z-\left(T+T^{\prime}-T^{\prime \prime}\right)\right)}+s^{\prime}\left(1-e^{-s\left(2 T^{\prime \prime}-\left(T+T^{\prime}\right)\right)}\right) e^{-s^{\prime}\left(z-T^{\prime \prime}\right)}\right) B^{\prime}(E(z)) d z$,

where $T$ and $T^{\prime}$ are still unknown. 


\subsection{The matching conditions}

We show in Appendix A that the matching conditions between the two stages of the problem write, in the case of an interior solution $0<T^{\prime}<\infty$ :

$$
\begin{aligned}
\lambda_{1-}^{*}\left(T^{\prime}\right) & =\lambda_{1+}^{*}\left(T^{\prime}\right) \\
\lambda_{2-}^{*}\left(T^{\prime}\right) & =\lambda_{2+}^{*}\left(T^{\prime}\right) \\
\left.\mathcal{H}_{-}^{*}\right|_{T^{\prime}}+\int_{0}^{T^{\prime}} \frac{\partial \mathcal{H}_{-}^{*}}{\partial T^{\prime}} d t & =\left.\mathcal{H}_{+}^{*}\right|_{T^{\prime}}-\int_{T^{\prime}}^{\infty} \frac{\partial \mathcal{H}_{+}^{*}}{\partial T^{\prime}} d t .
\end{aligned}
$$

In the case of a corner solution the last one of this conditions becomes an inequality. If the left-hand side of the inequality is greater than the right-hand side, the optimal solution is to sequester carbon in the agricultural soils permanently: $T^{\prime} \rightarrow \infty$. If the LHS is smaller than the RHS, the optimal solution is $T^{\prime}=0$ and then $T=0$ : it is never optimal to begin storing carbon in agricultural soils.

Using equations (12) and (24), equation (37) reduces to

$$
E\left(T_{-}^{\prime}\right)=E\left(T_{+}^{\prime}\right),
$$

which means that there is no jump in the emissions path at the switching time $T^{\prime}$.

Using equations (18) and (34), equation (38) writes

$$
\begin{aligned}
\lambda_{2-}(0)= & -\int_{0}^{T} e^{-r z} C^{\prime}(A(z)) d z-\frac{C^{\prime}(A(T))}{r}\left(e^{-r T}-e^{-r T^{\prime}}\right) \\
& -\int_{T^{\prime}}^{T^{\prime \prime}} e^{-r z} C^{\prime}(A(z)) d z-\frac{C^{\prime}\left(A\left(T^{\prime \prime}\right)\right)}{r} e^{-r T^{\prime \prime}} .
\end{aligned}
$$

We have, using equation (9),

$$
\begin{aligned}
\left.\mathcal{H}_{-}^{*}\right|_{T^{\prime}}+\int_{0}^{T^{\prime}} \frac{\partial \mathcal{H}_{-}^{*}}{\partial T^{\prime}} d t= & e^{-r T^{\prime}}\left(B\left(E\left(T^{\prime}\right)\right)-D\left(S\left(T^{\prime}\right)\right)-C\left(A\left(T^{\prime}\right)\right)\right)+\lambda_{1-}\left(T^{\prime}\right)\left(-\delta S\left(T^{\prime}\right)+E\left(T^{\prime}\right)\right) \\
& +\lambda_{2-}\left(T^{\prime}\right) a\left(T^{\prime}\right)-\widetilde{c} s \lambda_{1-}\left(T^{\prime}\right) \int_{0}^{T^{\prime}} a(t) e^{-s\left(T^{\prime}-t\right)} d t,
\end{aligned}
$$

and, using equation (21),

$$
\begin{aligned}
& \left.\mathcal{H}_{+}^{*}\right|_{T^{\prime}}-\int_{T^{\prime}}^{\infty} \frac{\partial \mathcal{H}_{+}^{*}}{\partial T^{\prime}} d t=e^{-r T^{\prime}}\left(B\left(E\left(T^{\prime}\right)\right)-D\left(S\left(T^{\prime}\right)\right)-C\left(A\left(T^{\prime}\right)\right)\right) \\
& +\lambda_{1+}\left(T^{\prime}\right)\left(-\delta S\left(T^{\prime}\right)+E\left(T^{\prime}\right)-\widetilde{c} s \int_{0}^{T^{\prime}} a(z) e^{-s\left(T^{\prime}-z\right)} d z\right)-\lambda_{2+}\left(T^{\prime}\right) b\left(T^{\prime}\right) \\
& +\widetilde{c} b\left(T^{\prime}\right) \int_{T^{\prime}}^{\infty} \lambda_{1+}(z)\left(s e^{-s\left(z-\chi\left(T^{\prime}\right)\right)}+s^{\prime}\left(1-e^{-s\left(T^{\prime}-\chi\left(T^{\prime}\right)\right)}\right) e^{-s^{\prime}\left(z-T^{\prime}\right)}\right) d z \\
& +\widetilde{c} s a\left(T^{\prime}\right) \int_{T^{\prime}}^{\infty} \lambda_{1+}(t) e^{-s\left(t-T^{\prime}\right)} d t \\
& -\widetilde{c} \int_{T^{\prime}}^{\infty} b(t)\left(\int_{t}^{\infty} \lambda_{1+}(z) \frac{\partial}{\partial T^{\prime}}\left(s e^{-s(z-\chi(t))}+s^{\prime}\left(1-e^{-s(t-\chi(t))}\right) e^{-s^{\prime}(z-t)}\right) d z\right) d t .
\end{aligned}
$$


We have $a\left(T^{\prime}\right)=0$ and $b(t)=\bar{a} \forall t \in\left[T^{\prime}, T^{\prime \prime}\right]$. After taking into account the first two matching conditions and simplifying, the last matching condition reduces to

$$
\begin{aligned}
0= & -\lambda_{2+}\left(T^{\prime}\right)+\widetilde{c} \int_{T^{\prime}}^{\infty} \lambda_{1+}(z)\left(s e^{-s(z-T)}+s^{\prime}\left(1-e^{-s\left(T^{\prime}-T\right)}\right) e^{-s^{\prime}\left(z-T^{\prime}\right)}\right) d z \\
& -\widetilde{c} \int_{T^{\prime}}^{T^{\prime \prime}}\left(\int_{t}^{\infty} \lambda_{1+}(z) s e^{-s\left(t-\left(T+T^{\prime}\right)\right)}\left(s e^{-s z}-s^{\prime} e^{\left(s^{\prime}-s\right) t-s^{\prime} z}\right) d z\right) d t .
\end{aligned}
$$

This equation can be simplified by changing the order of integration in the last integral and rearranging:

$$
\begin{aligned}
0= & -\lambda_{2+}\left(T^{\prime}\right)+\widetilde{c} \frac{2 s\left(s^{\prime}-s\right)}{s^{\prime}-2 s} e^{s\left(T+T^{\prime}\right)} \int_{T^{\prime}}^{\infty} \lambda_{1+}(z) e^{-2 s z} d z \\
& +\widetilde{c} s^{\prime} e^{s^{\prime} T^{\prime}}\left(1-\frac{s^{\prime}-s}{s^{\prime}-2 s} e^{-s\left(T^{\prime}-T\right)}\right) \int_{T^{\prime}}^{\infty} \lambda_{1+}(z) e^{-s^{\prime} z} d z
\end{aligned}
$$

$\lambda_{2+}\left(T^{\prime}\right)$ being given by equation (34) and $\lambda_{1+}(z)$ by equation (24). This last matching equation allows us to calculate $T^{\prime}$ as a function of $T$ and $T^{\prime \prime}$.

\subsection{The optimal dates}

It is now possible to find the optimal dates $T, T^{\prime}$ and $T^{\prime \prime}$, in the different configurations that can occur. In every configuration, these dates must obviously satisfy the following inequality:

$$
0 \leq T \leq \frac{B}{\bar{a}} \leq T^{\prime} \leq T^{\prime \prime} \leq T+T^{\prime} .
$$

Any meaningful combination of the different solutions below can take place.

- Interior solution

The date $T$ at which sequestration stops is $T_{2}<\frac{B}{\bar{a}}$, given by $\alpha(T)=0$, i.e., according to equations (19) and (41):

$$
\begin{aligned}
& \frac{C^{\prime}(A(T))}{r}\left(e^{-r T}-e^{-r T^{\prime}}\right)+\int_{T^{\prime}}^{T^{\prime \prime}} e^{-r z} C^{\prime}(A(z)) d z+\frac{C^{\prime}\left(A\left(T^{\prime \prime}\right)\right)}{r} e^{-r T^{\prime \prime}}= \\
& \widetilde{c} s e^{s T} \int_{T}^{T^{\prime}} e^{-(r+s) z} B^{\prime}(E(z)) d z .
\end{aligned}
$$

The date $T^{\prime \prime}$ at which de-sequestration stops is $T_{2}^{\prime \prime}<T+T^{\prime}$, given by $\beta\left(T^{\prime \prime}\right)=0$, i.e., according to equation (36):

$$
\begin{aligned}
\frac{C^{\prime}\left(A\left(T^{\prime \prime}\right)\right)}{r} e^{-r T^{\prime \prime}=} & \widetilde{c} s e^{-s\left(T^{\prime \prime}-\left(T+T^{\prime}\right)\right)} \int_{T^{\prime \prime}}^{\infty} e^{-(r+s) z} B^{\prime}(E(z)) d z \\
& +\widetilde{c} s^{\prime}\left(1-e^{-s\left(2 T^{\prime \prime}-\left(T+T^{\prime}\right)\right)}\right) e^{s^{\prime} T^{\prime \prime}} \int_{T^{\prime \prime}}^{\infty} e^{-\left(r+s^{\prime}\right) z} B^{\prime}(E(z)) d z
\end{aligned}
$$


The date $T^{\prime}$ at which de-sequestration begins is given by equation (42):

$$
\begin{aligned}
& \int_{T^{\prime}}^{T^{\prime \prime}} e^{-r z} C^{\prime}(A(z)) d z+\frac{C^{\prime}\left(A\left(T^{\prime \prime}\right)\right)}{r} e^{-r T^{\prime \prime}}= \\
& \widetilde{c} \frac{2 s\left(s^{\prime}-s\right)}{s^{\prime}-2 s} e^{s\left(T+T^{\prime}\right)} \int_{T^{\prime}}^{\infty} e^{-(r+2 s) z} B^{\prime}(E(z)) d z \\
& +\widetilde{c} s^{\prime} e^{s^{\prime} T^{\prime}}\left(1-\frac{s^{\prime}-s}{s^{\prime}-2 s} e^{-s\left(T^{\prime}-T\right)}\right) \int_{T^{\prime}}^{\infty} e^{-\left(r+s^{\prime}\right) z} B^{\prime}(E(z)) d z .
\end{aligned}
$$

- Corner solution after $T^{\prime}$

The date $T^{\prime \prime}$ at which de-sequestration stops becomes $T_{1}^{\prime \prime}=T+T^{\prime}$.

- Corner solution before $T^{\prime}$

The date $T$ at which sequestration stops becomes $T_{1}=\frac{B}{\bar{a}}$.

- Corner solution for $T^{\prime}$

It may happen that it is never optimal to begin to store carbon $\left(T^{\prime}=0\right)$ or that it is never optimal to release carbon in the atmosphere $\left(T^{\prime} \rightarrow \infty\right)$. In these two cases, the third matching condition (42) is no longer verified. As far as its left hand side is nil, the solution $T^{\prime} \rightarrow \infty$ prevails if the RHS is negative, and $T^{\prime}=0$ if it is positive.

It is not possible to solve explicitly and find the optimal dates in the general case that we study here. We will then use below specific functional forms and simulations.

\subsection{The stationary state}

This economy can admit two different steady states, according to the solution that prevails: no carbon release (formally, $T^{\prime} \rightarrow \infty$ or $\left.T^{\prime \prime}=T^{\prime}<\infty\right)$ and de-sequestration $\left(T^{\prime}<\infty, T^{\prime \prime}>T^{\prime}\right)$. In the two cases, the flow of carbon sequestered, the carbon stock and the emissions are given by:

$$
\begin{aligned}
F^{*} & =0, \\
S^{*} & =\frac{E^{*}}{\delta}, \\
D^{\prime}\left(\frac{E^{*}}{\delta}\right) & =(r+\delta) B^{\prime}\left(E^{*}\right),
\end{aligned}
$$

but the stock of land devoted to sequestration is different in the two cases:

$$
A^{*}=\left\{\begin{array}{l}
A(T) \text { if } T^{\prime} \rightarrow \infty \text { or } T^{\prime \prime}=T^{\prime}, \\
A\left(T^{\prime \prime}\right) \text { if } T^{\prime}<\infty \text { and } T^{\prime \prime}>T^{\prime} .
\end{array}\right.
$$

Equations (49) and (50) show that the steady state values of emissions and carbon stock are independant of the choices made about carbon sequestration in agricultural soils. Sequestration only affects the dynamics to reach the steady state. 
We now study this dynamics. The dynamic system writes:

$$
\left\{\begin{array}{l}
\dot{E}(t)=\frac{1}{B^{\prime \prime}(E(t))}\left((r+\delta) B^{\prime}(E(t))-D^{\prime}(S(t))\right) \\
\dot{S}(t)=-\delta S(t)+E(t)-F(t)
\end{array}\right.
$$

with $\lim _{t \rightarrow \infty} F(t)=0$ (cf. equations (17) and (31)).

Because of this last property, the dynamic system is asymptotically autonomous. Following Benaïm and Hirsch (1996), we first study the corresponding autonomous system and then examine the converging properties of the asymptotically autonomous system towards the autonomous one.

The autonomous system is

$$
\left\{\begin{array}{l}
\dot{E}(t)=\frac{1}{B^{\prime \prime}(E(t))}\left((r+\delta) B^{\prime}(E(t))-D^{\prime}(S(t))\right) \\
\dot{S}(t)=-\delta S(t)+E(t)
\end{array}\right.
$$

and its Jacobian matrix is

$$
J=\left(\begin{array}{ll}
r+\delta & -\frac{D^{\prime \prime}\left(S^{*}\right)}{B^{\prime \prime}\left(E^{*}\right)} \\
1 & -\delta
\end{array}\right)
$$

We have

$$
\left\{\begin{array}{l}
\operatorname{tr} J=r>0 \\
\operatorname{det} J=-(r+\delta) \delta+\frac{D^{\prime \prime}\left(S^{*}\right)}{B^{\prime \prime}\left(E^{*}\right)}
\end{array}\right.
$$

If $D^{\prime \prime}(S) \geq 0$ (constant or increasing marginal damage of carbon emissions), $\operatorname{det} J<0$; the stationary state is then a saddle-point. It is still the case when the marginal damage is decreasing but not too much, i.e. when $\frac{D^{\prime \prime}\left(S^{*}\right)}{B^{\prime \prime}\left(E^{*}\right)}<(r+\delta) \delta$.

A simple look at equations (17) and (31) is sufficient to convince us that $F(t)$ decreases at an asymptotic rate $e^{-s}$ when there is no carbon release, and at an asymptotic rate $e^{-\sup \left(s, s^{\prime}\right)}$ when there is some carbon release. Then, the solution of the dynamic system (51) converges to the solution of the autonomous system (52) at an asymptotic rate at least as fast as $e^{-s}$ in the first case, $e^{-\sup \left(s, s^{\prime}\right)}$ in the second one ${ }^{3}$. Moreover, since (51) converges asymptotically to (52), both will have the same local stability properties, and (51) will be saddle-point stable under the same conditions as (52).

\section{Numerical analysis}

\subsection{The optimal dates}

We suppose that the costs of sequestration are quadratic, the benefit of emissions log-linear, and the damage linear:

$$
\begin{gathered}
C(A(t))=\frac{\xi}{2} A(t)^{2}, \quad \xi>0, \\
B(E(t))=\phi \ln E(t), \quad \phi>0,
\end{gathered}
$$

\footnotetext{
${ }^{3}$ The proof is directly derived from the results in Benaïm and Hirsch (1996), and thus will be omitted here.
} 


$$
D(S(t))=\psi S(t), \quad \psi>0 .
$$

Whereas the first two assumptions do not constraint heavily the results, the assumption of a constant marginal damage is essential because it allows us to find an explicit solution to the problem.

According to equations (15) and (29) we have, both before and after $T^{\prime}$,

$$
\frac{\dot{E}(t)}{E(t)}=\frac{\psi}{\phi} E(t)-(r+\delta) .
$$

Besides, we know that emissions do not jump at $T^{\prime}$. The previous dynamic equation is unstable and so emissions take from the beginning their stationary value:

$$
E(t)=E^{*}=\frac{\phi(r+\delta)}{\psi} \quad \forall t .
$$

Along the whole path, emissions are constant and independant of the choices made otherwise about carbon sequestration in agricultural soils. They are naturally all the higher since the benefits are high, the interest and absorption rates are high and the marginal damage is low. This property of constancy of emissions along the optimal path greatly simplifies the resolution of the model and the determination of the optimal dates.

It implies immediately

$$
\begin{aligned}
& \lambda_{1-}(t)=-\frac{\psi}{r+\delta} e^{-r t}, \quad t \in\left[0, T^{\prime}[,\right. \\
& \lambda_{1+}(t)=-\frac{\psi}{r+\delta} e^{-r t}, \quad t \in\left[T^{\prime},+\infty[.\right.
\end{aligned}
$$

In the case of an interior solution, dates $T_{2}, T_{2}^{\prime \prime}$ and $T^{\prime}$ are respectively given by equations (45), (46) and (47), which can be written here as

$$
\begin{gathered}
\frac{\xi \bar{a} T}{r}+\frac{\xi \bar{a}}{r^{2}}\left(e^{-r\left(T^{\prime \prime}-T\right)}-e^{-r\left(T^{\prime}-T\right)}\right)=\frac{\widetilde{c} s \psi}{(r+\delta)(r+s)}\left(1-e^{-(r+s)\left(T^{\prime}-T\right)}\right), \\
\frac{\xi \bar{a}\left(T+T^{\prime}-T^{\prime \prime}\right)}{r}=\frac{\widetilde{c} s^{\prime} \psi}{(r+\delta)\left(r+s^{\prime}\right)}\left(1-\frac{r\left(s^{\prime}-s\right)}{s^{\prime}(r+s)} e^{-s\left(2 T^{\prime \prime}-\left(T+T^{\prime}\right)\right)}\right) \\
\frac{\xi \bar{a} T}{r}-\frac{\xi \bar{a}}{r^{2}}\left(1-e^{-r\left(T^{\prime \prime}-T^{\prime}\right)}\right)=\frac{\widetilde{c} s^{\prime} \psi}{(r+\delta)\left(r+s^{\prime}\right)}\left(1-\frac{r\left(s^{\prime}-s\right)}{s^{\prime}(r+s)} e^{-s\left(T^{\prime}-T\right)}\right) \\
+\frac{\widetilde{c} s \psi r\left(s^{\prime}-s\right)}{(r+\delta)(r+2 s)(r+s)\left(r+s^{\prime}\right)} e^{-s\left(T^{\prime}-T\right)}\left(1-e^{-(r+2 s)\left(T^{\prime \prime}-T^{\prime}\right)}\right) .
\end{gathered}
$$

These dates are independent of the characteristics of the benefit function: emission and sequestration choices are disconnected.

It is impossible to rule out a priori the possibility of multiple solutions (interior and corner ones) i.e. of local optima. To discriminate between them we will, in the numerical simulations, compute the total value function $\left(V_{-}+V_{+}\right)$.

We can go further in the analyical resolution when de-sequestration is faster than sequestration $\left(s^{\prime} \geq s\right)$. We show in Appendix B that an interior solution cannot exist, and that two different corner solutions can occur. 
- The first one implies $T^{\prime \prime}=T^{\prime}$, which means that de-sequestration stops exactly at the moment at which it begins, or in other words that de-sequestration never occurs. We can then find the value of the optimal $T_{2}$ :

$$
\widetilde{T}_{2}=\frac{\widetilde{c} s \psi r}{\xi \bar{a}(r+\delta)(r+s)} .
$$

$\widetilde{T}_{2}$ must be less than $\frac{B}{\bar{a}} 4 . \widetilde{T}_{2}$ is all the higher since the benefit in terms of sequestration given by the change of practice $\widetilde{c}$ is high, the marginal damage $\psi$ is high, the direct cost of sequestration $\xi$ and the adjustment cost $\bar{a}$ are low, and the absorption rate $\delta$ is low. Moreover, it is possible to show that $\widetilde{T}_{2}$ is an increasing function of the interest rate $r$ if and only if $s \delta>r^{2} . \widetilde{T}_{2}$ is independent of the value of the speed of de-sequestration $s^{\prime}$ (with $s^{\prime} \geq s$ ): in this case, the dissymmetry of the sequestration process does not affect the optimal solution.

Finally, $\widetilde{T}_{2}$ is an increasing function of the speed of absorption $s$, and we have

$$
\lim _{s \rightarrow \infty} \widetilde{T}_{2}=\frac{\widetilde{c} \psi r}{\xi \bar{a}(r+\delta)} .
$$

When we do not take into account the dynamics of sequestration, as in Feng et al. (2002), this date is the optimal date at which sequestration stops. We have $\frac{\lim _{s \rightarrow \infty} \widetilde{T}_{2}}{\widetilde{T}_{2}}=1+\frac{r}{s}$ : the error (overvaluation of the optimal period of sequestration) made by ignoring the dynamics of sequestration can be very significant.

- The second one is $T_{1}^{\prime \prime}=T_{2}+T^{\prime}$ : de-sequestration occurs until all land had returned to the usual practice. In this case, the optimal dates cannot be obtained explicitely.

It is impossible to find analytically which solution is the optimal one. We will compute in the numerical simulations the total value function $V_{-}+V_{+}$to discriminate between the two solutions, in the special case of our calibration.

\subsection{Numerical simulations}

\subsubsection{Calibration}

The numerical simulations are performed using the values of the parameters given in the table below.

According to FAO data ${ }^{5}$, the total agricultural land in the world is about 5 billion ha, and the total arable land and land under permanent crop is about 1.5 billion ha. Of this, we suppose that 1 billion ha can be used to store carbon $(B=1000 \mathrm{Mha})$. We also suppose that each year a change of practice can take place on 10 Mha $(\bar{a}=10 \mathrm{Mha})$, which means that the conversion of the total disposable land to carbon sequestration would take 100 years.

The initial stock of carbon in the atmosphere is $370 \mathrm{ppmv}$ (or about $778 \mathrm{GtC}$ ), the 2001 level. The model is calibrated to obtain a long term stock of $450 \mathrm{ppmv}$ (or about $947.25 \mathrm{GtC}$ ). For a rate of decay equal to 0.0125 (which means that the average life of carbon in the atmosphere is $1 / 0.0125=80$

\footnotetext{
${ }^{4}$ The solution is a corner solution before $T^{\prime},\left(T_{1}, T^{\prime}, T_{2}^{\prime \prime}=T^{\prime}\right)$, if and only if $\frac{\widetilde{c} s \psi r}{\xi \bar{a}(r+\delta)(r+s)} \geq \frac{B}{\bar{a}}$.

${ }^{5}$ Source: FAOSTAT database of Land Use Statistics.
} 


\begin{tabular}{lr}
\hline \hline Parameter & Value \\
\hline $\bar{a}$ & $10 \mathrm{Mha} / \mathrm{y}$ \\
$B$ & $1000 \mathrm{Mha}$ \\
$\tilde{c}$ & $0.015 \mathrm{GtC} / \mathrm{Mha}$ \\
$S_{0}$ & $370 \mathrm{ppmv}$ \\
$s$ & 0.02 \\
$\delta$ & 0.0125 \\
$r$ & 0.03 \\
$\psi$ & $10^{5}$ \\
$\xi$ & 1 \\
$\phi$ & 13235500 \\
\hline \hline
\end{tabular}

years), this requires stationary emissions of $450 \times 0.0125=5.625$ ppmv. As $E^{*}=\frac{\phi(r+\delta)}{\psi}$ we must have, if we choose $r=3 \%$ per year, $\frac{\phi}{\psi}=\frac{5.625}{0.0425}=132.355$.

According to the data reported in INRA (2002), a good estimation of the additional carbon that can be stored in agricultural land in France seems to be $15 \mathrm{tC} /$ ha. Even if this value can be different from one geographical area to another, we take here $\widetilde{c}=0.015 \mathrm{GtC} / \mathrm{Mha}$.

The same study for France allows us to evaluate the speeds of sequestration and de-sequestration: $s=0.02$ and $s^{\prime}=0.037$.

Finally, as units for total costs, benefits and damage are arbitrary, we take $\xi=1$. We then choose the decomposition between $\phi$ and $\psi$, satisfying the constraint $\frac{\phi}{\psi}=132.355$, such that the optimal date at which sequestration stops in the case $s=s^{\prime}=\infty$, given by equation (64), is significantly positive. With $\psi=10^{5}$ this date is around 20 years. We then have $\phi=132.35510^{5}$.

\subsubsection{Results}

When the speed of de-sequestration is higher than the speed of sequestration, the optimal solution always consists in storing carbon in agricultural soils permanently, without any release (figure 2). If the speed of de-sequestration was lower, it would be optimal to store carbon during a longer period of time and then release some carbon. For $s=0.02$ and $s^{\prime}=0.01$ for instance, carbon is stored in the soils during about 30 years, then release begins immediately and stops 12 years or so later. For $s=0.02$ and $\forall s^{\prime}>s$, the computation of the total value function shows that the optimal solution is the first corner solution $\left(T=T^{\prime}=T^{\prime \prime}\right)$. Carbon is stored during about 20 years and never released.

These results can be explained intuitively. If carbon release is a very slow process (slower than storage), de-sequestration induces an immediate benefit as the cost associated to sequestration disappears, while the damage will appear only gradually. The parameter $s^{\prime}$ acts as a discount rate concerning the damage. However, physical data of the sequestration process $\left(s^{\prime}>s\right)$ rule out this kind of solution. Then, when de-sequestration is fast, it is never optimal to release carbon after having stored it. Optimal sequestration is permanent. 


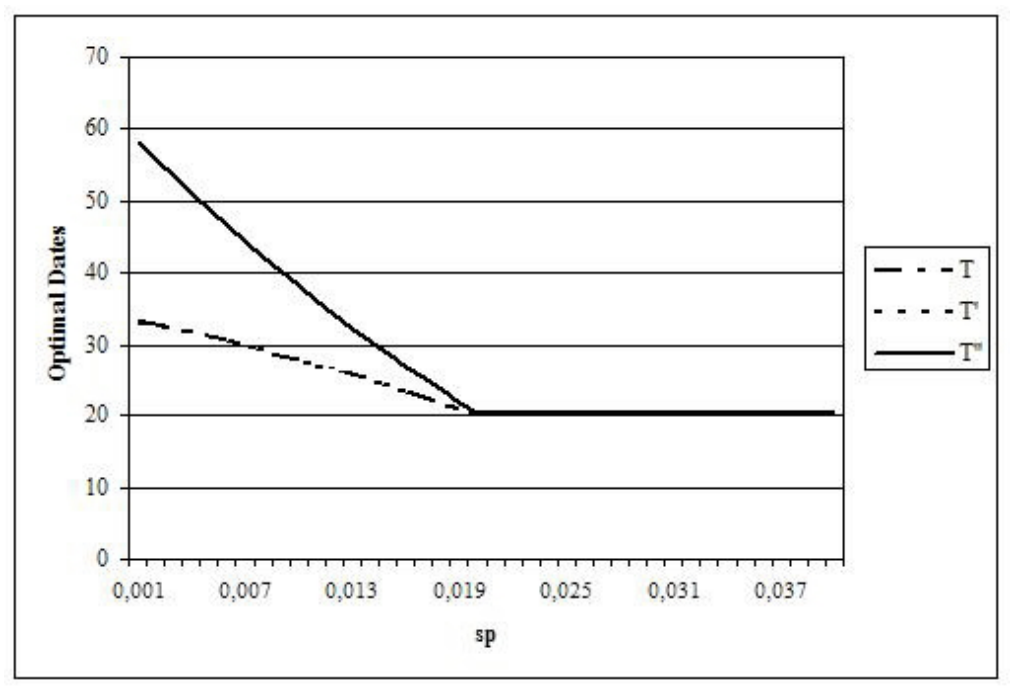

Figure 2: The optimal dates

With the assumption $s=s^{\prime}=\infty$, in other terms when the dynamics of sequestation is ignored (case studied by Feng et al. (2002)), the optimal sequestration is equivalent to half the physical potential sequestration ( $T=50$ years $\Leftrightarrow A=500$ Mha). Whereas this optimal effort corresponds to the fifth of the potential ( $T=20$ years $\Leftrightarrow A=200 \mathrm{Mha}$ ) for speeds of sequestration and de-sequestration close to the empirical French ones $\left(s=0.02\right.$ and $\left.s^{\prime}=0.03\right)$. We see that the error made when not taking into account the dynamics of sequestration is very significant, with an error coefficient $\left(1+\frac{r}{s}\right)$ of 2.5 for our calibration.

Figures 3 and 4 show respectively the flow of carbon emissions trapped and the additional carbon stock stored when we assume that these last values of $s$ and $s^{\prime}$ are good proxis for the world conditions and for these two sequestration efforts $(T=50$ and $T=20)$.

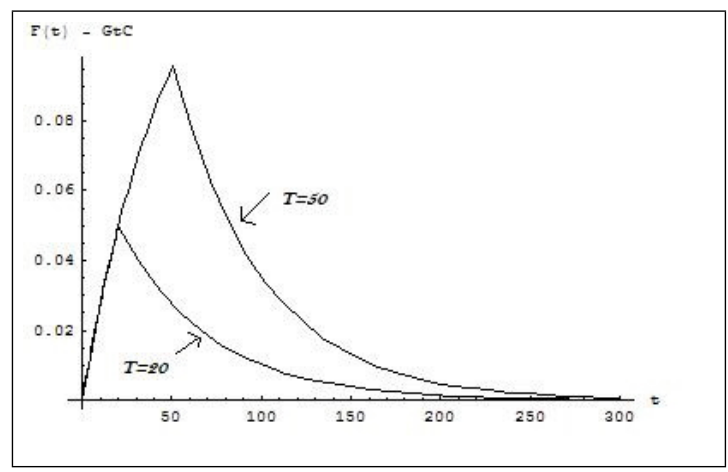

Figure 3: Flow of carbon trapped

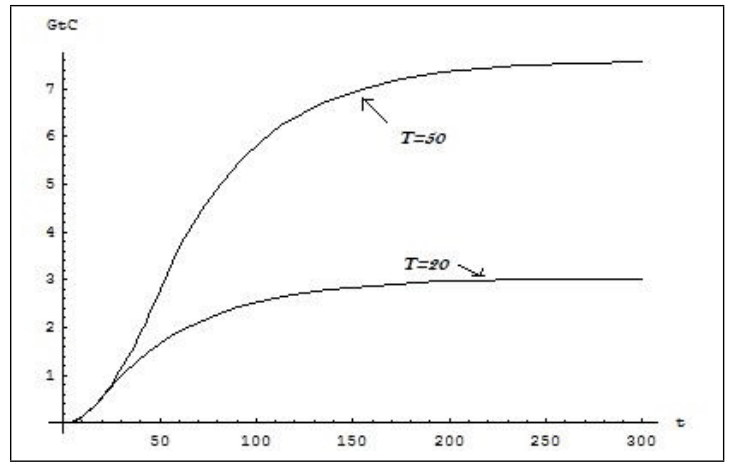

Figure 4: Additional carbon stock sequestered 
The additional carbon stock sequestered converges to a steady level of 7.5 GtC when we don't take the dynamics of the physical process into consideration in the determination of the optimal policy $(T=50)$, while the optimal long term level is only $3 \mathrm{GtC}(T=20)$. The omission of the dynamic process leads to a very significant over-sequestration.

\section{Conclusion}

This paper takes explicitely into account the temporality of sequestration. Its first contribution is technical. We solve an optimal control problem with two stages and a dissymmetric dynamic process. The second contribution is empirical. We show that the error made when sequestration is supposed immediate can be very significant. We also exhibit numerically the optimal path of sequestation, which must be permanent if sequestration is faster than de-sequestration, for specific benefit, damage and cost functions, and a calibration that mimics roughly the world conditions.

Interesting extensions would consist in considering factors that could make the optimal sequestation temporary, even in the case of a release faster than storage, like technical progress in abatement, or technical progress in usual practices and not in sequestering practices, that could increase the cost of sequestration.

\section{References}

Benaïm M. and M.W. Hirsch (1996), "Asymptotic pseudotrajectories and chain recurrent flows with applications", Journal of Dynamics and Differential Equations, 8, 141-176.

European Climate Change Programme (2003), Working Group on Sinks Related to Agricultural Soils - Final report.

Feng H, J. Zhao and C. Kling (2002), "The Time Path and Implementation of Carbon Sequestration", American Journal of Agricultural Economics, 84, 134-149.

Hénin S.et M. Dupuit (1945), "Essai de bilan de la matière organique du sol", Annales Agronomiques, $\mathrm{n}^{\circ} 15,147-157$.

INRA (2002), Increasing carbon stocks in French agricultural soils?, Report for the French Ministry for Ecology and Sustainable Development, October.

IPCC (2000), Land use, Land-use change and forestry (LULUCF), Cambridge University Press, U.K. Lal R., J.M. Kimble, R.F. Follet and C.V. Cole (1998), The potential of US cropland to sequester carbon and mitigate the greenhouse effect. Ann Arbor Press, Chelsea, MI.

Saglam H.C. (2002), "Optimal pattern of technology adoption under embodiement with a finite planning horizon: A multi-stage optimal control approach", IRES, Université Catholique de Louvain.

Smith P., J.U. Smith and D.S. Powlson (1996), Soil Organic Matter Network: 1996 Model and Experimental Metadata. GCTE Report 7, GCTE Focus 3, Wallingford, Oxon.

Tomiyama K. (1985), "Two-Stage Optimal Control Problems and Optimality Conditions", Journal of Economic Dynamics and Control, 9, 317-337. 
Tomiyama K. and R. Rossana (1989), "Two-Stage Optimal Control Problems with an Explicit Switch

Point Dependence: Optimality Criteria and an Example of Delivery Lags and Investment", Journal of Economic Dynamics and Control, 13, 319-337.

\section{A The two-stage optimal control problem with an integral equation of motion}

The optimal control problem we study here has two distinctive features: (i) the accumulation of the state variable is dissymmetric and we must determine the switching point between the two stages of accumulation and desaccumulation; (ii) the motion of the state variable depends on the integral of a function of the past values of the control. The question is to check how to define properly the Hamiltonian function corresponding to this problem, and how to write the first order necessary conditions and the matching conditions. We use a method close to the one developped in Saglam (2002) for a technology adoption problem.

\section{A.1 Problem before $T^{\prime}$}

$$
\begin{aligned}
\max V_{-} & =\int_{0}^{T^{\prime}} F_{-}(C(t), K(t), t) d t+V_{+}^{*}\left(K\left(T^{\prime}\right), T^{\prime}\right) \\
\dot{K}(t) & =f_{-}(C(t), K(t), t)+\int_{0}^{t} g_{-}(C(z), t, z) d z, \quad 0 \leq t<T^{\prime} \\
K(0) & =K_{0} \text { given, } K\left(T^{\prime}\right) \text { free, }
\end{aligned}
$$

where $K$ is the vector of state variables, $C$ the vector of control variables, and $T^{\prime}$ the switching time. Notice that this switching time appears explicitly in the equation of motion of the state variable.

The Lagrangian of this problem is

$$
\Lambda_{-}=V_{-}+\int_{0}^{T^{\prime}} \lambda_{-}(t)\left(f_{-}(C(t), K(t), t)+\int_{0}^{t} g_{-}(C(z), t, z) d z-\dot{K}(t)\right) d t
$$

or, after changing the order of integration in the second term of the integral and integrating by parts the third one:

$$
\begin{aligned}
\Lambda_{-}= & \int_{0}^{T^{\prime}} F_{-}(C(t), K(t), t) d t+\int_{0}^{T^{\prime}} \lambda_{-}(t) f_{-}(C(t), K(t), t) d t \\
& +\int_{0}^{T^{\prime}}\left(\int_{t}^{T^{\prime}} \lambda_{-}(z) g_{-}(C(t), z, t) d z\right) d t \\
& -\left(\lambda_{-}\left(T^{\prime}\right) K\left(T^{\prime}\right)-\lambda_{-}(0) K(0)\right)+\int_{0}^{T^{\prime}} \dot{\lambda}_{-}(t) K(t) d t \\
& +V_{+}^{*}\left(K\left(T^{\prime}\right), T^{\prime}\right) .
\end{aligned}
$$

Let the Hamiltonian be defined by

$$
\begin{aligned}
\mathcal{H}_{-}\left(C(t), K(t), t, T^{\prime}\right)= & F_{-}(C(t), K(t), t)+\lambda_{-}(t) f_{-}(C(t), K(t), t) \\
& +\int_{t}^{T^{\prime}} \lambda_{-}(z) g_{-}(C(t), z, t) d z .
\end{aligned}
$$


Then we can write

$$
\Lambda_{-}=\int_{0}^{T^{\prime}}\left(\mathcal{H}_{-}+\dot{\lambda}_{-}(t) K(t)\right) d t-\left(\lambda_{-}\left(T^{\prime}\right) K\left(T^{\prime}\right)-\lambda_{-}(0) K(0)\right)+V_{+}^{*}\left(K\left(T^{\prime}\right), T^{\prime}\right) .
$$

Let $\left(C^{*}(t), K^{*}(t)\right)$ be an optimal path $\forall t \in\left[0, T^{\prime}\left[\right.\right.$ and $T^{*} \in\left[0, \infty\left[\right.\right.$. We perturb the $C^{*}(t)$ path by an arbitrary $\Delta C(t)$; it generates, through the equation of motion, a perturbation of the $K^{*}(t)$ path and of the optimal switching time $T^{\prime *}: C(t)=C^{*}(t)+\varepsilon \Delta C(t), K\left(T^{\prime}\right)=K\left(T^{* *}\right)+\varepsilon \Delta K\left(T^{\prime}\right)$, $T^{\prime}=T^{* *}+\varepsilon \Delta T^{\prime}($ Saglam $(2002))$.

We then have

$$
\begin{aligned}
\frac{\partial \Lambda_{-}}{\partial \varepsilon}= & \left(\left.\mathcal{H}_{-}\right|_{T^{\prime}}+\dot{\lambda}_{-}\left(T^{\prime}\right) K\left(T^{\prime}\right)\right) \Delta T^{\prime}+\int_{0}^{T^{\prime}}\left(\frac{\partial \mathcal{H}_{-}}{\partial C(t)} \Delta C(t)+\frac{\partial \mathcal{H}_{-}}{\partial K(t)} \Delta K(t)+\frac{\partial \mathcal{H}_{-}}{\partial T^{\prime}} \Delta T^{\prime}\right) d t \\
& +\int_{0}^{T^{\prime}} \dot{\lambda}_{-}(t) \Delta K(t) d t-\lambda_{-}\left(T^{\prime}\right) \Delta K\left(T^{\prime}\right)-\dot{\lambda}_{-}\left(T^{\prime}\right) K\left(T^{\prime}\right) \Delta T^{\prime} \\
& +\frac{\partial V_{+}^{*}}{\partial K\left(T^{\prime}\right)} \Delta K\left(T^{\prime}\right)+\frac{\partial V_{+}^{*}}{\partial T^{\prime}} \Delta T^{\prime} \\
= & \left(\left.\mathcal{H}_{-}\right|_{T^{\prime}}+\int_{0}^{T^{\prime}} \frac{\partial \mathcal{H}_{-}}{\partial T^{\prime}} d t+\frac{\partial V_{+}^{*}}{\partial T^{\prime}}\right) \Delta T^{\prime}+\int_{0}^{T^{\prime}} \frac{\partial \mathcal{H}_{-}}{\partial C(t)} \Delta C(t) d t \\
& +\int_{0}^{T^{\prime}}\left(\frac{\partial \mathcal{H}_{-}}{\partial K(t)}+\dot{\lambda}_{-}(t)\right) \Delta K(t) d t+\left(\frac{\partial V_{+}^{*}}{\partial K\left(T^{\prime}\right)}-\lambda_{-}\left(T^{\prime}\right)\right) \Delta K\left(T^{\prime}\right) .
\end{aligned}
$$

Each component of this derivative must be equal to zero. This allows us to write the usual first order necessary conditions and the matching conditions:

- first order necessary conditions:

$$
\begin{aligned}
\frac{\partial \mathcal{H}_{-}}{\partial C(t)} & =0 \\
\frac{\partial \mathcal{H}_{-}}{\partial K(t)}+\dot{\lambda}_{-}(t) & =0
\end{aligned}
$$

- matching conditions:

$$
\begin{aligned}
\left.\mathcal{H}_{-}\right|_{T^{\prime}}+\int_{0}^{T^{\prime}} \frac{\partial \mathcal{H}_{-}}{\partial T^{\prime}} d t+\frac{\partial V_{+}^{*}}{\partial T^{\prime}} & =0 \\
\frac{\partial V_{+}^{*}}{\partial K\left(T^{\prime}\right)}-\lambda_{-}\left(T^{\prime}\right) & =0 .
\end{aligned}
$$

\section{A.2 Problem after $T^{\prime}$}

$$
\begin{aligned}
\max V_{+}= & \int_{T^{\prime}}^{\infty} F_{+}(C(t), K(t), t) d t \\
\dot{K}(t)= & f_{+}\left(C(t), K(t), t, T^{\prime}\right)+\int_{T^{\prime}}^{t} g_{+}\left(C(z), t, z, T^{\prime}\right) d z, \quad T^{\prime} \leq t \\
& K\left(T^{\prime}\right) \text { given. }
\end{aligned}
$$


Lagrangian of this problem:

$$
\begin{aligned}
\Lambda_{+}= & V_{+}+\int_{T^{\prime}}^{\infty} \lambda_{+}(t)\left(f_{+}\left(C(t), K(t), t, T^{\prime}\right)+\int_{T^{\prime}}^{t} g_{+}\left(C(z), t, z, T^{\prime}\right) d z-\dot{K}(t)\right) d t \\
= & V_{+}+\int_{T^{\prime}}^{\infty} \lambda_{+}(t) f_{+}\left(C(t), K(t), t, T^{\prime}\right) d t+\int_{T^{\prime}}^{\infty}\left(\int_{t}^{\infty} \lambda_{+}(z) g_{+}\left(C(t), z, t, T^{\prime}\right) d z\right) d t \\
& -\left(\lim _{t \rightarrow \infty} \lambda_{+}(t) K(t)-\lambda_{+}\left(T^{\prime}\right) K\left(T^{\prime}\right)\right)+\int_{T^{\prime}}^{\infty} \dot{\lambda}_{+}(t) K(t) d t .
\end{aligned}
$$

Definition of the Hamiltonian:

$\mathcal{H}_{+}\left(C(t), K(t), t, T^{\prime}\right)=F_{+}(C(t), K(t), t)+\lambda_{+}(t) f_{+}\left(C(t), K(t), t, T^{\prime}\right)+\int_{t}^{\infty} \lambda_{+}(z) g_{+}\left(C(t), z, t, T^{\prime}\right) d z$.

First order necessary conditions:

$$
\begin{aligned}
\frac{\partial \mathcal{H}_{+}}{\partial C(t)} & =0 \\
\frac{\partial \mathcal{H}_{+}}{\partial K(t)}+\dot{\lambda}_{+}(t) & =0 .
\end{aligned}
$$

We can write the objective as

$$
\Lambda_{+}=\int_{T^{\prime}}^{\infty}\left(\mathcal{H}_{+}+\dot{\lambda}_{+}(t) K(t)\right) d t-\left(\lim _{t \rightarrow \infty} \lambda_{+}(t) K(t)-\lambda_{+}\left(T^{\prime}\right) K\left(T^{\prime}\right)\right) .
$$

Besides, we have

$$
\frac{d V_{+}^{*}}{d T^{\prime}}=\frac{\partial V_{+}^{*}}{\partial K\left(T^{\prime}\right)} \frac{\partial K\left(T^{\prime}\right)}{\partial T^{\prime}}+\frac{\partial V_{+}^{*}}{\partial T^{\prime}}
$$

with

$$
\begin{aligned}
\frac{d V_{+}^{*}}{d T^{\prime}} & =\frac{d \Lambda_{+}^{*}}{d T^{\prime}} \\
& =-\left.\mathcal{H}_{+}^{*}\right|_{T^{\prime}}-\dot{\lambda}_{+}^{*}\left(T^{\prime}\right) K^{*}\left(T^{\prime}\right)+\int_{T^{\prime}}^{\infty} \frac{\partial \mathcal{H}_{+}^{*}}{\partial T^{\prime}} d t+\lambda_{+}^{*}\left(T^{\prime}\right) \frac{\partial K\left(T^{\prime}\right)}{\partial T^{\prime}}+\dot{\lambda}_{+}^{*}\left(T^{\prime}\right) K^{*}\left(T^{\prime}\right) .
\end{aligned}
$$

So we can write

$$
\begin{aligned}
\frac{\partial V_{+}^{*}}{\partial K\left(T^{\prime}\right)} & =\lambda_{+}^{*}\left(T^{\prime}\right) \\
\frac{\partial V_{+}^{*}}{\partial T^{\prime}} & =-\left.\mathcal{H}_{+}^{*}\right|_{T^{\prime}}+\int_{T^{\prime}}^{\infty} \frac{\partial \mathcal{H}_{+}^{*}}{\partial T^{\prime}} d t .
\end{aligned}
$$

Finally, the matching conditions can be written as follows:

$$
\begin{aligned}
\lambda_{-}^{*}\left(T^{\prime}\right) & =\lambda_{+}^{*}\left(T^{\prime}\right) \\
\left.\mathcal{H}_{-}\right|_{T^{\prime}}+\int_{0}^{T^{\prime}} \frac{\partial \mathcal{H}_{-}}{\partial T^{\prime}} d t & =\left.\mathcal{H}_{+}^{*}\right|_{T^{\prime}}-\int_{T^{\prime}}^{\infty} \frac{\partial \mathcal{H}_{+}^{*}}{\partial T^{\prime}} d t .
\end{aligned}
$$

Transversality condition:

$$
\lim _{t \rightarrow \infty} \lambda_{+}(t) K(t)=0
$$




\section{A.3 Application}

The previous results are applied to our problem, with the following definition of the variables and functions:

$$
\begin{gathered}
C(t)=\left(\begin{array}{c}
E(t) \\
a(t)
\end{array}\right), \quad K(t)=\left(\begin{array}{c}
S(t) \\
A(t)
\end{array}\right) \\
F_{-}(C(t), K(t), t)=e^{-r t}(B(E(t))-D(S(t))-C(A(t))) \\
f_{1-}(C(t), K(t), t)=-\delta S(t)+E(t) \\
f_{2-}(C(t), K(t), t)=a(t) \\
g_{1-}(C(z), t, z)=-\widetilde{c} s a(z) e^{-s(t-z)} \\
g_{2-}(C(z), t, z)=0 \\
F_{+}(C(t), K(t), t)=F_{-}(C(t), K(t), t) \\
f_{1+}\left(C(t), K(t), t, T^{\prime}\right)=-\delta S(t)+E(t)-\widetilde{c} s \int_{0}^{T^{\prime}} a(z) e^{-s(t-z)} d z \\
f_{2+}\left(C(t), K(t), t, T^{\prime}\right)=-b(t) \\
g_{1+}\left(C(z), t, z, T^{\prime}\right)=\widetilde{c} b(z)\left(s e^{-s(t-\chi(z))}+s^{\prime}\left(1-e^{-s(z-\chi(z))}\right) e^{-s^{\prime}(t-z)}\right) \\
g_{2+}\left(C(z), t, z, T^{\prime}\right)=0 .
\end{gathered}
$$

\section{B Analytical solution for the specific functional forms when $s^{\prime} \geq s$}

\section{B.1 Interior solution}

We first show that there is no interior solution for $s^{\prime} \geq s$.

Equations (61) and (62) imply

$$
\begin{aligned}
& -\frac{\xi \bar{a}\left(T^{\prime \prime}-T^{\prime}\right)}{r}+\frac{\xi \bar{a}}{r^{2}}\left(1-e^{-r\left(T^{\prime \prime}-T^{\prime}\right)}\right) \\
= & \frac{\widetilde{c} \psi s^{\prime}}{(r+\delta)\left(r+s^{\prime}\right)}\left(1-\frac{r\left(s^{\prime}-s\right)}{s^{\prime}(r+s)} e^{-s\left(2 T^{\prime \prime}-T-T^{\prime}\right)}\right) \\
& -\frac{\widetilde{c} \psi s^{\prime}}{(r+\delta)\left(r+s^{\prime}\right)}\left(1-\frac{r\left(s^{\prime}-s\right)}{s^{\prime}(r+s)} e^{-s\left(T^{\prime}-T\right)}\right) \\
& -\frac{\widetilde{c} s \psi r\left(s^{\prime}-s\right)}{(r+\delta)(r+2 s)(r+s)\left(r+s^{\prime}\right)} e^{-s\left(T^{\prime}-T\right)}\left(1-e^{-(r+2 s)\left(T^{\prime \prime}-T^{\prime}\right)}\right),
\end{aligned}
$$

which can be written, with $X=T^{\prime \prime}-T^{\prime} \geq 0, F(X)=1-e^{-r X}-r X$ and $G(X)=1-e^{-2 s X}-$ $\frac{s}{r+2 s}\left(1-e^{-(r+2 s) X}\right)$,

$$
\frac{\xi \bar{a}}{r^{2}} F(X)=\frac{\widetilde{c} \psi r\left(s^{\prime}-s\right)}{(r+\delta)(r+s)\left(r+s^{\prime}\right)} e^{-s\left(T^{\prime}-T\right)} G(X)
$$


The LHS of this equality has the same sign as $F(X)$, and the sign of the RHS depends on the sign of $s^{\prime}-s$ and $G(X)$.

We show easily that $F(X) \leq 0$ and $G(X) \geq 0 \forall X \geq 0: F(0)=0$ and $F^{\prime}(X)=r\left(e^{-r X}-1\right)<0$ $\forall X>0 ; G(0)=0$ and $G^{\prime}(X)=s e^{-2 s X}\left(2-e^{-r X}\right)>0 \forall X \geq 0$.

When $s^{\prime}>s$, the only solution is then $X=0$ i.e. $T^{\prime \prime}=T^{\prime}$. For $s^{\prime}=s$ the equality reduces to $F(X)=0$, and the only solution is again $T^{\prime \prime}=T^{\prime}$.

For $s^{\prime} \geq s$ and $T^{\prime \prime}=T^{\prime}$, equations (61) and (62) become identical. The optimal dates $T$ and $T^{\prime}$ are then solution of the system composed of this last equation and (60):

$$
\left\{\begin{array}{l}
\frac{\xi \bar{a} T}{r}=\frac{\widetilde{c} \psi s}{(r+\delta)(r+s)}\left(1-e^{-(r+s)\left(T^{\prime}-T\right)}\right) \\
\frac{\xi \bar{a} T}{r}=\frac{\widetilde{c} \psi s^{\prime}}{(r+\delta)\left(r+s^{\prime}\right)}\left(1-\frac{r\left(s^{\prime}-s\right)}{s^{\prime}(r+s)} e^{-s\left(T^{\prime}-T\right)}\right) .
\end{array}\right.
$$

The elimination of $\frac{\xi \bar{a} T}{r}$ between these two equations yields

$$
\frac{r\left(s^{\prime}-s\right)}{r+s^{\prime}}\left(1-e^{-s\left(T^{\prime}-T\right)}\right)=-s e^{-(r+s)\left(T^{\prime}-T\right)},
$$

which is impossible for $T^{\prime} \in[T, \infty[$ since the LHS is positive and the RHS strictly negative.

\section{B.2 Corner solutions}

We now examine the corner solutions.

There can first exist a corner solution before $T^{\prime}$. Then, equations (61) and (62) are valid and imply as before $T^{\prime \prime}=T^{\prime}$, i.e. no de-sequestration. The date $T$ at which sequestration stops can take two values: $T^{\prime}$ or $\frac{B}{\bar{a}}$.

If $T=T^{\prime},(61)$ and (62) become identical and allow us to obtain

$$
\tilde{T}_{2}=\frac{\widetilde{c} \psi s r}{\xi \bar{a}(r+\delta)(r+s)} .
$$

We obtain the same value $\tilde{T}_{2}$ for a corner solution both before and after $T^{\prime}\left(T=T^{\prime}=T^{\prime \prime}\right)$.

This solution is valid as long as $\tilde{T}_{2}<\frac{B}{\bar{a}}$, i.e. as long as $\frac{\widetilde{c} \psi s r}{\xi(r+\delta)(r+s)}<B$.

If $T=\frac{B}{\bar{a}}$, we have

$$
e^{-s T^{\prime}}=e^{-s \frac{B}{\bar{a}}}\left(\frac{\xi(r+\delta)(r+s)\left(r+s^{\prime}\right)}{\widetilde{c} \psi s^{\prime} r\left(s-s^{\prime}\right)}-\frac{s^{\prime}(r+s)}{r\left(s-s^{\prime}\right)}\right)
$$

which requires $B<\frac{\widetilde{c} \psi s^{\prime} r}{\xi(r+\delta)\left(r+s^{\prime}\right)}$. The solutions $T=\frac{B}{\bar{a}}$ and $T=\tilde{T}_{2}$ can coexist for $\frac{\widetilde{c} \psi s r}{\xi(r+\delta)(r+s)}<B<$ $\frac{\widetilde{c} \psi s^{\prime} r}{\xi(r+\delta)\left(r+s^{\prime}\right)}$. The corner solution before $T^{\prime}\left(T=\frac{B}{\bar{a}}\right)$ and $T^{\prime \prime}=T^{\prime}$ gives the same result.

There can also exist a corner solution after $T^{\prime}, T_{1}^{\prime \prime}=T_{2}+T^{\prime}$, but in this case we cannot obtain the optimal dates analytically. 